\title{
CONTROLE QUÍMICO DA HELMINTOSPORIOSE (Bipolaris incurvata) EM COQUEIRO CULTIVAR ‘ANÃO-VERDE’ EM CONDIÇÕES DE CAMPO'
}

\author{
JUNIOR CESAR MODESTO² \& ROSELI CHELA FENILLE ${ }^{3}$
}

\begin{abstract}
RESUMO - Avaliou-se a eficácia de fungicidas para o controle da helmintosporiose (Bipolaris incurvata) do coqueiro, em condições de campo. O experimento foi conduzido em Ocauçu - SP, em plantas com 8 meses de idade. Foram realizadas três pulverizações com intervalo quinzenal, utilizandose de 600 litros de calda/ha, com os ingredientes ativos: prothioconazole $(0,100$ e $0,150 \mathrm{~L} / \mathrm{ha})$, tebuconazole $(0,150$ e $0,200 \mathrm{~L} / \mathrm{ha})$ e propiconazole $(0,125$ e $0,250 \mathrm{~L} / \mathrm{ha}$ ). A primeira pulverização foi realizada em plantas com sintomas foliares da doença, de modo que todas as plantas avaliadas tinham as folhas velhas como fonte de inóculo. O controle proporcionado pelos ingredientes ativos, foi avaliado em folhas jovens que, sob condições climáticas favoráveis, foram suscetíveis ao ataque do patógeno. Constatou-se que todos os fungicidas e doses utilizados foram eficientes no controle da helmintosporiose (Bipolaris incurvata).
\end{abstract}

Termo para indexação: helmintosporioses, tebuconazole, propiconazole, prothioconazole, Cocos nucifera.

\section{CHEMICAL CONTROL OF Bipolaris incurvata IN COCONUT CV. 'ANÃO-VERDE’ UNDER FIELD CONDITIONS}

ABSTRACT - Helmintosporiose fungicide control efficacy was evaluated in coconut plants, at field conditions. The experiment was conducted in Ocauçu-SP (Brasil), using 8-months old plants. Three sprayings were applied, within 15 days intervals, with 600 liters of spray volume/ha. The treatments were defined by three doses of the following fungicides: prothioconazole $(0.100$ and $0.150 \mathrm{~L} / \mathrm{ha})$, tebuconazole $(0.150$ and $0.200 \mathrm{~L} / \mathrm{ha})$ and propiconazole $(0.125$ and $0.250 \mathrm{~L} / \mathrm{ha})$. The first spray was in symptomatic plants, therefore every evaluated plant had its old leaves as the inoculum source. The disease index evaluation was done in young leaves, which are susceptible to this pathogen under favorable environment conditions. All the fungicides and their doses used were efficient in controlling helmintosporiose leaf spot, except for their respective check-treatments (control treatments).

Index termas: Bipolaris incurvata, tebuconazole, propiconazole, prothioconazole, Cocos nucifera.

O coqueiro (Cocos nucifera L.) constitui-se numa das mais importantes culturas perenes capazes de gerar sistema auto-sustentável de exploração, explorado em mais de 86 países. No Brasil, a cultura do coqueiro apresentou, nos últimos anos, crescente interesse pelos produtores em diversos Estados, considerados não-tradicionais nesse cultivo, como: Minas Gerais, São Paulo, Rio de Janeiro, Espírito Santo, Goiás, Mato Grosso e Mato Grosso do Sul (Gutiérrez-Cuenca \& Siqueira, 2002).

Nas condições brasileiras, a cultura do coqueiro pode ser infectada por diversos patógenos, causadores de inúmeras doenças, sendo dificultadas as pesquisas na área de fitopatologia pelo longo período de incubação de certas moléstias e peculiaridades dos agentes etiológicos (Warwick et al., 1998).

De acordo com Warwick et al. (1998), a Helmintosporiose (Bipolaris incurvata (C. Bernard) Alcorn manifesta-se principalmente em viveiros, favorecida pela alta umidade relativa, pouco arejamento e temperatura entre 18 a $27^{\circ} \mathrm{C}$. Nas folhas, $B$. incurvata causa lesões pequenas, de forma elíptica, cor marrom, com halo amarelo-ouro, desenvolvendo-se inicialmente nas folhas inferiores, progredindo para a parte superior da planta. Em casos severos, as lesões coalescem, e as margens dos folíolos ficam necróticas. Os métodos de controle baseiamse em preventivo, fiscalização efetiva do plantio, adubação balanceada sem excesso de nitrogênio, eliminação das ervas daninhas, aumento da aeração, além do tratamento químico.

Os conídios do fungo B. incurvata apresentam alta viabilidade, podendo germinar por longo período. Segundo Fagan (1987), 43\% de conídios germinaram com 90 dias após a produção, $62 \%$ germinaram com 59 dias e $90 \%$ germinaram com 24 dias; a alta capacidade de germinação pode ser extrapolada para as condições de campo, onde $60 \%$ dos conídios podem germinar nas folhas do coqueiro por período de até 3 meses, proporcionando dano menor em folhas velhas (Brown, 1975).

A incidência do patógeno $B$. incurvata sobre as folhas do coqueiro pode estar relacionada com a nutrição da planta, principalmente as mais novas, de até 2 anos. A aplicação de nitrogênio em viveiro aumentou a suscetibilidade da planta à doença (Gallasch, 1987)

A importância social da cultura do coqueiro no Brasil, principalmente para a região Nordeste, justifica o esforço da pesquisa sobre os aspectos fitotécnicos e fitossanitários para se obterem melhores rendimentos. Objetivou-se, no presente estudo, avaliar a eficiência de diferentes fungicidas no controle da helmintosporiose em coqueiro cv. anão-verde.

A pesquisa foi conduzida em condições de campo, na fazenda Ouro Verde, no município de Ocauçu - SP, em coqueiros cv. Anão-Verde. Utilizaram-se plantas novas com idade aproximada de 8 meses, cultivadas no espaçamento de 7,5 m X 7,5 m e irrigadas por gotejamento. Tratos culturais como: adubação e controle de plantas daninhas foram adotados de acordo com as recomendações de Ferreira et al. (1998), Fontes \& Ferreira (2002).

Como a helmintosporiose se manifesta principalmente em plantas de viveiro e plantios novos, implantou-se o experimento em área com coqueiros novos infectados pelo patógeno, e evidenciando os sintomas foliares da doença.

Os tratamentos para o controle da B. incurvata basearam-se em diferentes fungicidas e concentrações: (testemunha, prothioconazole 0,100 e $0,150 \mathrm{~L} / \mathrm{ha}$, tebuconazole 0,150 e $0,200 \mathrm{~L} /$ ha e propiconazole 0,125 e $0,250 \mathrm{~L} / \mathrm{ha}$ ). O delineamento experimental utilizado foi o de blocos ao acaso, com quatro repetições e sete tratamentos. Cada parcela foi constituída de sete plantas, cinco úteis e duas bordaduras.

Efetuou-se a aplicação dos tratamentos no período da manhã, sem presença de orvalho e vento, com pulverizador de $\mathrm{CO}_{2}$, pressão de $40 \mathrm{lib} / \mathrm{pol}^{2}$, usando o volume de calda de $600 \mathrm{~L} / \mathrm{ha}$. Adicionou-se o surfatante não-iônico de Alquil - fenol - poliglicoléter, na concentração de $0,05 \%$ p.c.

A aplicação dos tratamentos químicos para o controle da helmintosporiose iniciou-se no dia 19-10-01. Para tanto, foram selecionadas e marcadas folhas jovens no início da emissão da gema terminal, com o objetivo de acompanhar o desenvolvimento do patógeno, pois, com a emissão foliar, ocorre o aparecimento dos folíolos, sendo estes constituídos de tecido vegetal novo, o qual, em condições climáticas favoráveis, torna-se suscetível à infecção do patógeno.

Na Tabela 1, verifica-se que os folíolos, no início da emissão foliar, se encontravam com o número reduzido de lesões, em média, menos

\footnotetext{
${ }^{1}$ (Trabalho 133/2003). Recebido: 19/09/2003. Aceito para publicação: 21/07/2004.

${ }^{2}$ Botagro Consultoria Agropecuária, CEP 18640-000, Pardinho - SP, junior.modesto@ uol.com.br.

${ }^{3}$ Laboratório de Apoio Vegetal, DFA-GO, MAPA, CEP 74003-010, Goiânia - GO, roselifenille@agricultura.gov.br
} 
TABELA 1 - Número de lesões de helmintosporiose (Bipolaris incurvata) (C.Bernard) Alcorn, em folhas de coqueiro (Cocos nucifera L.) cv. AnãoVerde. Ocauçu-SP, 2001.

\begin{tabular}{|c|c|c|c|c|}
\hline \multirow[t]{2}{*}{ TRATAMENTOS } & \multicolumn{4}{|c|}{ Número de lesões em folhas $^{1}$} \\
\hline & $19-10-01^{2}$ & $03-11-01^{2}$ & $18-11-01^{2}$ & $04-12-01^{2}$ \\
\hline 1 - Testemunha (água) & $1,36^{3} \mathrm{a}$ & $56,82 \mathrm{a}$ & 94,94 a & $160,29 \mathrm{a}$ \\
\hline 2 - Prothioconazole $(0,100 \mathrm{~L} / \mathrm{ha})$ & $1,00 \mathrm{a}$ & 2,07 & $4,77 \quad b$ & 9,13 \\
\hline 3 - Prothioconazole $(0,150 \mathrm{~L} / \mathrm{ha})$ & 1,17 a & 2,93 & 3,89 b & 5,85 \\
\hline 4 - Tebuconazole $(0,150 \mathrm{~L} / \mathrm{ha})$ & 1,56 a & 6,31 & 7,46 b & 13,21 \\
\hline 5 - Tebuconazole $(0,200 \mathrm{~L} / \mathrm{ha})$ & 1,36 a & 4,48 & $8,74 \mathrm{~b}$ & 12,78 \\
\hline 6 - Propiconazole $(0,125 \mathrm{~L} / \mathrm{ha})$ & $1,36 \mathrm{a}$ & 1,59 & $4,49 \quad b$ & 11,83 \\
\hline 7 - Propiconazole $(0,250 \mathrm{~L} / \mathrm{ha})$ & $1,00 \mathrm{a}$ & 1,36 & $2,81 \quad b$ & 6,94 \\
\hline D.M.S (5\%) & 0,33 & 2,86 & 3,57 & 2,57 \\
\hline Coeficiente de variação (\%) & 12,29 & 52,89 & 51,25 & 27,88 \\
\hline
\end{tabular}

${ }^{1}$ Valores transformados em raiz quadrada de $(\mathrm{X}+0.5)$

${ }^{2}$ Aplicação dos tratamentos

${ }^{3}$ Médias seguidas de mesma letra na coluna não diferem estatisticamente entre si, pelo teste de Tukey, a 5\% de significância

de duas lesões de helmintosporiose em cada folha; o tecido, portanto, apresentava colonização reduzida, quando comparado com as folhas velhas do mesmo vegetal.

Na primeira avaliação, o número de lesões nas folhas selecionadas não diferiu significativamente, sendo ideal para a implantação dos tratamentos químicos, estabelecendo intervalo de avaliação e reaplicação dos fungicidas a cada 15 dias.

Todas as plantas selecionadas apresentavam nas folhas velhas grande número de lesões do patógeno, que podiam ser fontes de inóculo. $\mathrm{Na}$ testemunha com o tecido vegetal novo, houve colonização pelo patógeno e, no período de 15 dias (03/11/01), na folha selecionada da testemunha, o número de lesões aumentou significativamente, passando de 1,36 para 56,82 lesões /folha.

A aplicação dos diferentes tratamentos químicos foi eficiente no controle da helmintosporiose, visto que o número de lesões, em todos os tratamentos, foi significativamente inferior ao da testemunha (Tabela 1).

Totalizando 60 dias de avaliações, o número de lesões do patógeno na testemunha aumentou significativamente, atingindo 160,29 por folha (Tabela 1), ao passo que, em todos os tratamentos químicos, houve proteção no tecido vegetal foliar, impedindo a colonização dos folíolos pelo patógeno.

Para as condições edafoclimáticas e com base nos resultados obtidos, pode-se concluir que, com a aplicação dos tratamentos químicos, não houve evolução da doença em folhas de coqueiro cv. Anão-Verde e que os fungicidas prothioconazole, tebuconazole e propiconazole foram eficientes no controle da Bipolaris incurvata.

\section{REFERÊNCIAS BIBLIOGRÁFICAS}

BROWN, J.S. Investigation of some coconut leaf spots in Papua New Guinea. Papua New Guinea Agricultural Journal, Konedobu,v.2, n. 26, p.43, 1975.

FAGAN, H.J. Influence of microclimate on Drechslera feaf spot of young coconuts: effects of desiccation on spore survival and of moisture and shade on infection and diseases development. Annals of Applied Biology, Wellesbourne, v.111, n.3., p.521-533, 1987.

FERREIRA, J.M.S.M; WARWICK, D.R.N.; SIQUEIRA, L.A. A cultura do coqueiro no Brasil. 2.ed. Brasília: EMBRAPA, 1998. 292p.

FONTES, H.R.; FERREIRA, J.M.S. Recomendações técnicas para a produção de mudas de coqueiro. In: GUTIÉRREZ-CUENCA, M.A.; SIQUEIRA, L.A. Cultivo do coco da Bahia. Goiânia: Agência Rural, 2002.

GALLASCH, H. Effect of nutrition on the incidence of Drechslera incurvata leaf spot of coconuts. Papua New Guinea Agricultural Journal, Konedolu, v.3-4, n. 25, p.38-50, 1987.

GUTIÉRREZ-CUENCA, M.A., SIQUEIRA, L.A. Aspectos da comercialização e mercados do coco. In: CURSO PARCERIA EMBRAPA/AGÊNCIA RURAL Cultivo do coco-da-baía. Goiânia: Agência Rural, 2002.

WARWICK, D.R.N.; LEAL, E.C.; RAM, C. Doenças do coqueiro. In: FERREIRA, J.M.S.MWARWICK, D.R.N., SIQUEIRA, L.A. Acultura do coqueiro no Brasil. 2. ed. Brasília: EMBRAPA, 1998. Cap.9, p.269-289. 